\title{
The reconstruction of root canal using biological dentin post
}

\begin{abstract}
Biological posts may be a good alternative instead of conventional post systems. The aim of this study was to evaluate the effects of clinical procedures used for biological dentin post on root canal. A 55-year-old male patient was referred to the Department of Endodontics, Dicle University, Diyarbakır, Turkey with a complaint of extensive caries in the right mandibular premolar tooth. Endodontic obturation was done using gutta-percha and root canal sealer (Sealapex, Kerr, Canada). A freshly extracted tooth was then sectioned bucco-lingually along the long axis using a diamond disk. Post space was created by fiber post drill. Suitable fiber post size and length was measured with digital caliper. The biological dentin post was modified with this measurement. Following satisfactory adaptation of the biological post clinically and radiographically, the post was cemented into the root canal using self-adhesive dual cure resin cement (Panavia F, Kuraray, Japan). The core of tooth structure was built with composite resin (Filtek Bulk Fill Posterior, 3M ESPE, USA) after that a porcelain crown was adapted on tooth. For the sixth month no any clinical and radiographic pathology was observed in the assessment. This case report has proved functional rehabilitation of a damaged endodontically treated tooth using a biological dentin post.
\end{abstract}

Volume 9 Issue 6 - 2018

\author{
Seda Falakaloğlu, Özkan Adıgüzel, Gökhan \\ Özdemir \\ Department of Endodontics, Dicle University, Turkey
}

Correspondence: Seda Falakaloğlu, Department of Endodontics, Faculty of Dentistry, Dicle University, Turkey, Email sedafelakaloglu@gmail.com

Received: November 18, 2017 | Published: November 20,

\section{Introduction}

In endodontic treatment cases, little of the original tooth structure remains as a result of trauma, caries, prior restoration, and endodontic procedures. ${ }^{1}$ Consequently, the appointment of a post is necessary for core retantion. For intracanal retantion and stability of coronal restoration, using posts made from different materials such as fiber glass, carbon fiber, metal and ceramic. ${ }^{2}$ The material from which the post is constructed is important in the biomechanical performance of root canal-treated teeth. In spite of varied types of commercially effective posts, nothing from that group meet all the ideal biological and mechanical properties. Biological posts may be a good alternative instead of conventional post systems. ${ }^{3}$ Because the aim of biomimetics in restorative dentistry is to return all of the prepared dental tissues to functional biologic and esthetic result by biological materials. "Biological Post" serves biocomponent section for intraradicular rehabilitation of a fractured endodontically treated tooth. The use of biological posts is an alternative for the strengthening of the root canal, protects the internal dentin walls of the root canal, presents total biocompatibility and adapts to conduct configuration. ${ }^{4}$ The aim of this study was to evaluate the effects of clinical procedures used for biological dentin post on root canal.

\section{Case report}

A 55-year-old male patient was referred to the Department of Endodontics, Dicle University, Diyarbakır, Turkey with a complaint of extensive caries in the right mandibular premolar tooth. After clinical and radiographic examinations, local anesthesia was given and a rubber dam was placed in isolation of the operative area. The access cavity was opened and the length of the root canal was determined by apex locator. For irrigation by $\% 2.5 \mathrm{NaOCl}$ and \% 17 EDTA was applied. Endodontic obturation was done using gutta-percha and root canal sealer (Sealapex, Kerr, Canada) (Figure 1). A freshly extracted tooth which was autoclaved at $121^{\circ} \mathrm{C}$ for 15 minutes was then sectioned bucco-lingually along the long axis using a diamond disk (Figure 2). Post space was created by fiber post drill. Suitable fiber post size and length was measured with digital caliper. The biological dentin post was modified with this measurement (Figure 3). Following satisfactory adaptation of the biological post clinically and radiographically, the post was cemented into the root canal using selfadhesive dual cure resin cement (Panavia F, Kuraray, Japan) (Figure 4). The core of tooth structure was built with composite resin (Filtek Bulk Fill Posterior, 3M ESPE, USA) after that a porcelain crown was adapted on tooth. For the sixth month no any clinical and radiographic pathology was observed in the assessment (Figure 5).

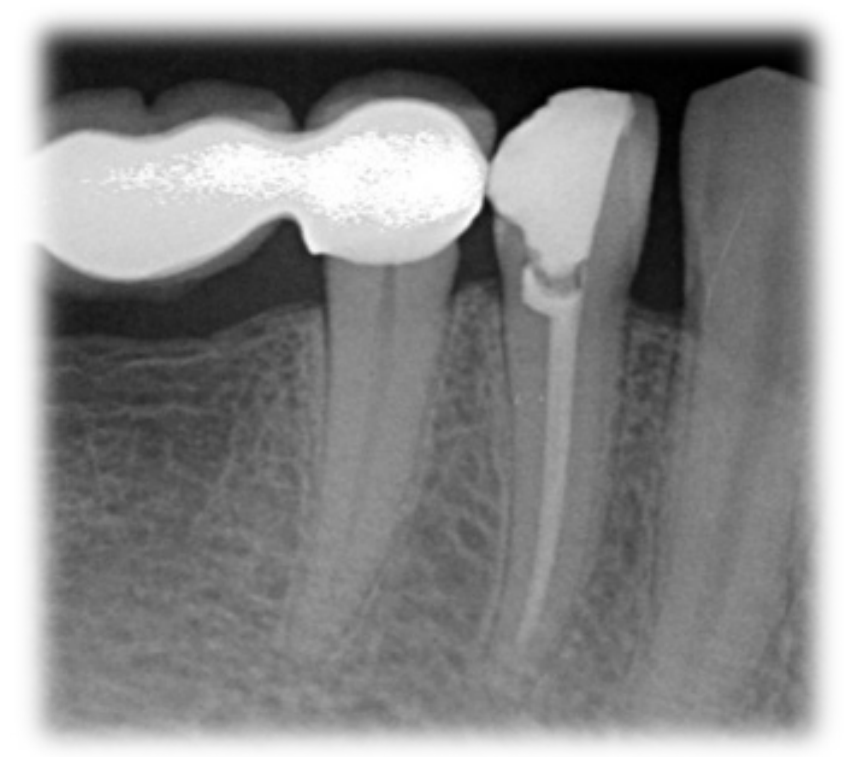

Figure I Endodontic obturation was done using gutta-percha and root cana sealer. 


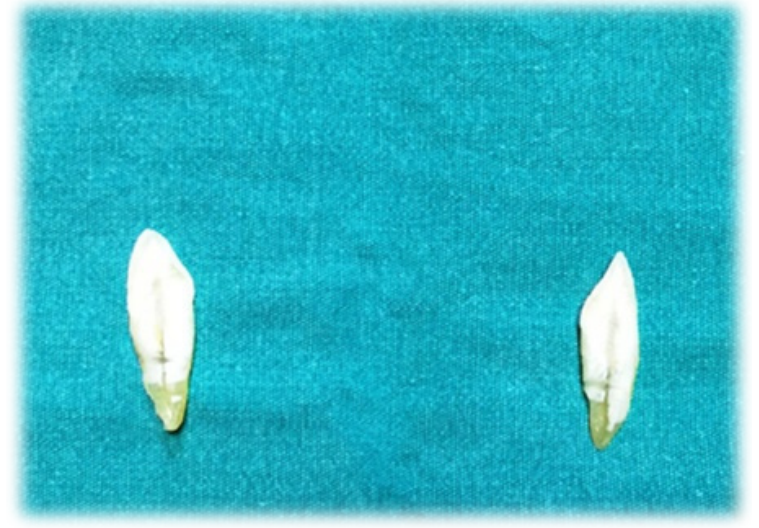

Figure $2 \mathrm{~A}$ freshly extracted tooth which was autoclaved at $121^{\circ} \mathrm{C}$ for 15 minutes was then sectioned bucco-lingually along the long axis using a diamond disk.

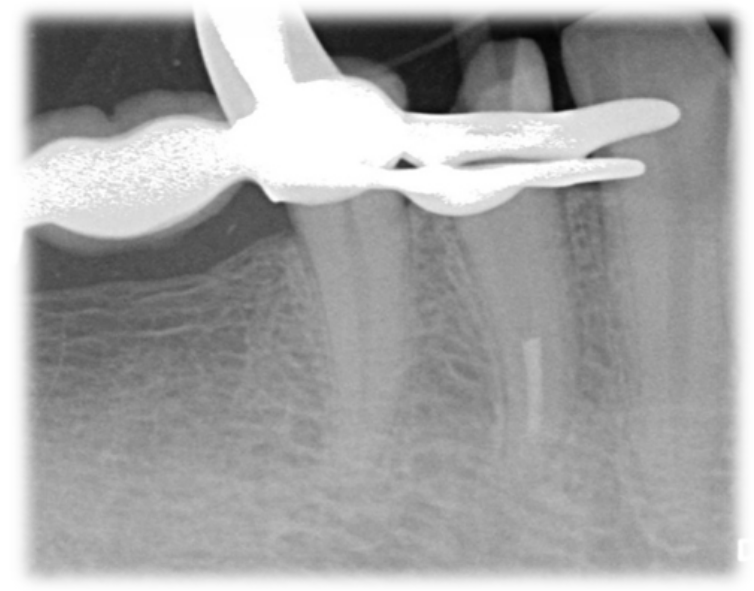

Figure 4 Self $\square$ adhesive dual cure resin cement.

\section{Discussion}

This case report has proved functional rehabilitation of a damaged endodontically treated tooth using a biological dentin post. Biological dentin posts made from extracted tooth allocate for adaptation to the root canal and would not attempt stress to the dentin, since they contain the same biomechanical properties as the restored teeth. ${ }^{5}$ Conventional post systems are made from steel and titanium increased risk of vertical root fructure because of higher elastic modulus than dentin. ${ }^{6}$ Otherwise fiber posts have lower elastic modulus but they may rise the risk of debonding. ${ }^{7}$ The adhesion among the biological dentin post with the cement, and the dental structure allows to attain monoblock biomechanical system with materials. It was founded that biological dentin posts arranged better stress distribution than stainless steel or glass fiber post by Belli at all, also are made from extracted tooth due to low cost. Additionally, all the fracture patterns observed could be repairable. However, this study showed that biological dentin posts do not strenghten the fracture resistance of teeth..$^{8-12}$ Unfortunately, this is an important disadvantage for biological dentin post. In spite of this, further studies can assess the long-term biomechanical demeanure of the biological posts so as to be sure the benefits of this technique and

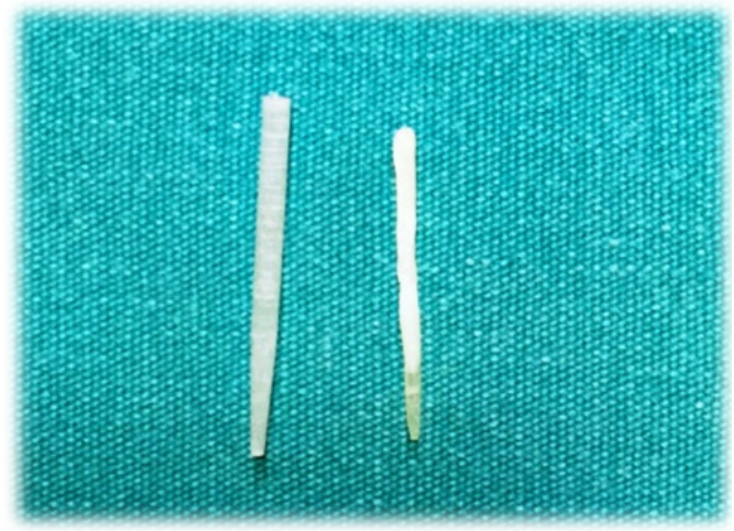

Figure 3 The biological dentin post was modified with this measurement.

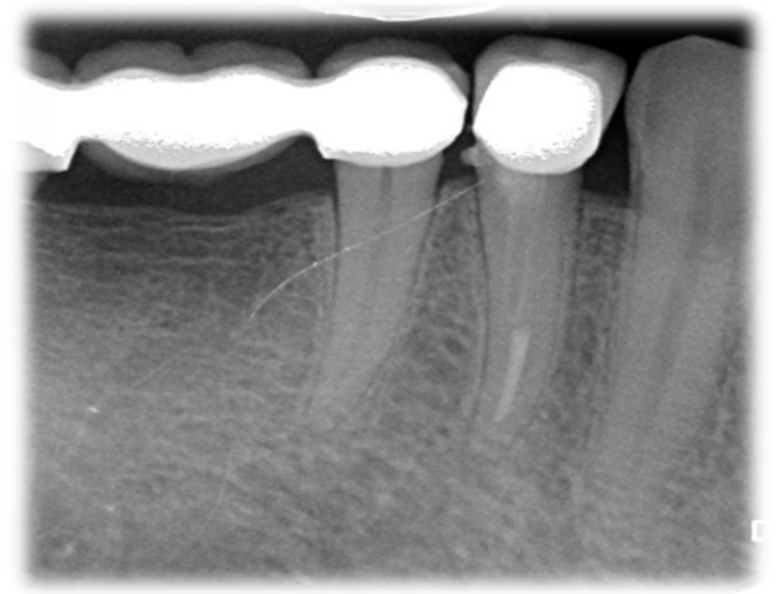

Figure 5 Clinical and radiographic pathology was observed in the assessment.

make it an useful treatment option, particularly for the lower economy group of patients ${ }^{13}$ Also this technique combined the benefits of recent technology (CAD/CAM) to replicate original tooth form and anatomy. ${ }^{14}$ Concerning with the ethical aspect, it is necessary to clarify to the patient that the post is made from sterilized extracted teeth, thus preventing biosecurity risks. Following infection control protocol, risks should be bloked. ${ }^{15,16}$

\section{Conclusion}

On our clinical significance and based on scientific results, biological dentin post may become visible a acknowledged alternative than other available post materials.

\section{Acknowledegments}

None.

\section{Conflict of interest}

The author decflares that there is no conflcit of interest. 


\section{References}

1. Sorensen JA, Martinoff JT. Intracoronal reinforcement and coronal coverage: a study of endodontically treated teeth. J Prosthet Dent. 1984;51:780-784.

2. Silva GR, Santos-Filho PC, Simamoto-Júnior PC, et al. Effect of post type and restorative techniques on the strain and fracture resistance of flared incisor roots. Braz Dent J. 2011;22(3):230-237.

3. Correa-Faria P, Alcantara CE, Caldas-Diniz MV, et al. Biological Restoration: Root Canal and Coronal Reconstruction. J Esthet Restor Dent. 2010;22(3):168-177.

4. Kathuria A, Kavitha M, Khetarpal S. Ex vivo fracture resistance of endodontically treated maxillary central incisors restored with fiberreinforced composite posts and experimental dentin posts. J Conserv Dent. 2011;14(4):401-405.

5. Swarupa CH, Sajjan SG, Bhupathiraju VL, et al. Biological dentin post for intra radicular rehabilitation of a fractured anterior tooth. J Clin Diagn Res. 2014;8(2):242-243.

6. Isidor, Flemming, Per Ödman, et al. Intermittent loading of teeth restored using prefabricated carbon fiber posts. Int J Prosthodont. 1996;9(2):131-136.

7. Meira, Josete BC. Elastic modulus of posts and the risk of root fracture. Dental Traumatology. 2009:394-398.

8. Belli Sema, Kezban Celik, Makbule Bigle, et al. Are dentin posts biomechanically intensive?: A laboratory and FEA study." Journal of Adhesion Science and Technology. 2014;28(4):2365-2377.
9. Carlos Eduardo Pinto Alcântara, Patrícia Corrêa-Faria, Walison Arthuso Vasconcelloslcântara Carlos Eduardo Pinto. Combined technique with dentin post reinforcement and original fragment reattachment for the esthetic recovery of a fractured anterior tooth: a case report. Dental Traumatology. 2010;26(5):447-450.

10. Imparato JCP. Restorations in anterior primary teeth: An alternative technique through gluing of natural crowns." J bras odontoped odontol bebe. 1998:63-72.

11. Kaizer OB. Utilization of biological posts to reconstruct weakened roots. Rev Gaucha Odontol. 2008;56:7-13.

12. Batista A, Lopes CG. Performed dentin post reinforcing teeth with immature apexes. Rev Bras Prot Clin Lab. 1999;3:199-221.

13. Mishra N, Narang I. Bio-reconstruction of root canal using dentin post. Saudi Endod J. 2013;3(2):87-89.

14. Yadav, Kanika. Endodontic Management of a Mandibular First Molar with Radix Entomolaris and Conservative Post-endodontic Restoration with CAD/CAM Onlay: A Novel Clinical Technique. Journal of clinical and diagnostic research. JCDR. 2016:10(11):ZD13-ZD15.

15. Busato AL. Biological restorations using tooth fragments. American journal of dentistry. 1998;11(1):46.

16. Yang, Zu-Pyn, Che-Shoa Chang. A 3-year follow-up of a homotransplanted tooth from a tooth bank. Journal of endodontics. 1990;16(1):34-37. 